\title{
The next generation of knowledge management: Implications for LIS educators and professionals
}

\author{
Jay Liebowitz, Harrisburg University of Science and Technology, USA, \\ JLiebowitz@harrisburgu.edu \\ Joanna Paliszkiewicz, Warsaw University of Life Sciences - SGGW, Poland, \\ Joanna_paliszkiewicz@sggw.pl
}

\begin{abstract}
Knowledge Management (KM) has been an evolving field over the past 35 years. We have seen the field emerge from developing the institutional memory of the organization to increasing innovation to building more internal and external effectiveness. The Library and Information Science (LIS) community has had a great role to play in KM, and as we reflect on the progress of $K M$ over the years, we can learn from our past and project towards the future. The aim of the paper is to present the overview: what is the history, what is the situation now and what is the future of knowledge management in the next five years.
\end{abstract}

Keywords: Knowledge management, information science, LIS, KM, education, KM technology, KM applications, KM policy.

\section{Introduction}

Knowledge is one of the key assets that needs to be properly managed in organizations (Paliszkiewicz, 2007). Researchers and practitioners emphasize the value of knowledge management (Jantz, 2001) as a critical source of an organization's long-term sustainability (Nonaka, 1991; Nonaka \& Takeuchi, 1995; Wiig, 1997). The past decades have seen extensive research on knowledge and knowledge management (Koening, 2002; Ma \& Kuo-Hsun, 2010; Tuomi, 2002, Scholl, König, Meyer, \& Heisig, 2004). Knowledge management has become an independent academic field, but this subject has a high degree of interactions with other disciplines, such as library and information science.

The aim of the paper is to present the overview: what is the history, what is the situation now and what is the future of knowledge management in the next five years. The authors focus on the trends related to technologies, applications, education, and policy. Implications for LIS educators and professionals are presented.

\section{Where We Have Been--KM and Information Science in the Past}

Over the years, there have been many comparisons between KM and information science (IS). The seminal work of Borko (1968) defined information science as:

"...that discipline that investigates the properties and behavior of information, the forces governing the flow of information, and the means of processing information for optimum 
accessibility and usability. It is concerned with the body of knowledge relating to the origination, collection, organization, storage, retrieval, interpretation, transmission, and utilization of information. (p. 3)

If you substitute "information" with "knowledge", it sounds like this could also be relevant for defining "knowledge management". In fact, Onyancha and Ocholla (2009) performed research to see what are the top 100 subject terms to describe the KM literature. They found that the top two subject terms were: "information resources management" (555 articles) and "information science" (417 articles). More recently, Wang, Zhu, Song, Hou, and Zhang (2018) found that "Information Science/Library Science" was second (1723 articles, 22.6\% of the total) in terms of being in the top $30 \mathrm{KM}$ categories ranked by the number of publications. "Management" was the first subject category with 2334 articles (30.6\% of the total). Wang et al. (2018) also visualized the academic discipline of KM by showing the co-words network of author keywords in KM articles published from 1974-2017.

Goswami and Agrawal (2018) looked at where KM articles were published in 11 key journals over the years. Separately, Gaviria-Marin, Merigo, and Popa (2018) performed a bibliometric analysis of Journal of Knowledge Management publications between 1997 and 2016. They found that the USA (229 papers) and the UK (163 papers) lead the publications in this journal.

KM has progressed through four generations to date. The first generation focused on "Personal KM" to improve the individual's ability to best capture, share, apply, and leverage one's knowledge (Pauleen, 2009) The second generation focused on "collection and codification" in order to expand the individual's KM capabilities to organizational effectiveness. As we progressed further, the third generation of KM concentrated on knowledge collaboration and social networking. Movement away from codification to more collaboration and social networking enabled organizations to innovate and generate knowledge, particularly across disciplines and functional silos (Liebowitz, 2012). Currently, we are suggesting that we are in the fourth generation of KM where we are bringing in Artificial Intelligence (AI), machine learning, data analytics, Internet of Things (IoT), and other emerging developments.

Every organization by now should be doing KM, without even calling it KM. Liebowitz (1999) published the first Handbook on KM back in 1999, and by now, organizations should have already integrated KM into their everyday activities. Even though the number of published KM articles has dropped since 2012 (Liebowitz, 2016) and we see a great upward trend of Big Data and Analytics articles (Liebowitz, 2018), you still see many KM jobs listed. For example, last year Liebowitz looked at three major job search engines of KM jobs (Indeed, SimplyHired, \& Burning Glass) just in the U.S. and there were about 1.8 million KM jobs. So, there still is interest in KM, even though it may not be as dominant as an academic field.

From the KM perspective, KM and analytics can form some strong synergies. Each community can learn from each other. One ripe area for integration is intuition-based decision making (Gigerenzer, 2008; Liebowitz, 2014; Liebowitz, Paliszkiewicz, \& Goluchowski, 2017; Liebowitz, 2019), leaning heavily on KM and experiential learning backgrounds may be a way to bridge this gap. AI is another key area for integration with KM. Over the years, there have been many springs and winters of AI. Right now, AI is having a great resurgence where China wants to be the leader in AI by 2030 and the Chinese government is investing heavily in this 
technology. Also, Massachusetts Institute of Technology (MIT) announced that they are investing $\$ 1$ billion to form a new College of Computing to further advance AI technology. Hopefully, we will keep a symbiotic relationship between people and technology and leverage the capabilities of each.

\section{Where We Are Now}

KM has been a growing field with immense potential. It has become an important part of the management field due to:

- A number of scientific and research books related to KM authors such as: Davenport and Prusak (1998), Nonaka and Takeuchi (2000), Tiwana (2000), Leonard-Barton et al. (2014), Liebowitz (2016), Paliszkiewicz (2019).

- An increase in the number of scientific papers and papers which publish scientific and expert works on KM (for example in the Scopus database, we can find more than 300,000 articles, which in the title, abstract or keywords use the words knowledge management).

- A continuous increase in the number of conferences, seminars and workshops over the years, through KMWorld, The International Institute for Applied Knowledge Management (IIAKM), IFLA, APQC, ICKM, and others.

- An increased number of researchers in the area of KM (particularly in large corporations) and increasing use of KM in practice (particularly in profit and non-profit organizations).

- An increased use of KM ideas in resolving problems in developing new knowledge in other scientific fields, for example in medicine, law, etc.

- And incorporation of KM into undergraduate, and postgraduate studies at numerous colleges or universities.

According to Greene (2019), KM is very important especially, when we consider these statistics that poor knowledge-sharing practices cost Fortune 500 companies $\$ 31.5$ billion annually and that $74 \%$ of organizations estimate that effective knowledge management disciplines increase company productivity by $10-40 \%$.

Knowledge as an asset is important in efficiency and productivity and it is critical that organizations manage it effectively. Many of the multinational companies have already invested in knowledge management systems (KM, 2018):

- General Electric (GE) has a Corporate Executive Council (CEC) to help executives share information and improve their decision-making.

- Microsoft has a project Skills Planning Development (SPUD) built to maintain employee competencies in order to gain a strategic advantage over competitors.

- Ernst \& Young (EY) has a project called an Accelerated Solutions Environment which involves the rapid application of knowledge, models and approaches to client situations. 


\section{Where We Are Heading in the Next Five Years for KM}

\section{KM Technologies}

KM technologies have changed dramatically over the last decade, but the basic needs of KM have not changed: the ability to capture, share, apply, and create knowledge to improve organizational activities. The new generation of KM technologies are up to the digital challenge (Patel, 2015). Today's KM solutions are built to run in the cloud, gather information efficiently, with content management capabilities to collect data from different sources, and utilize search software to quickly deliver it to users at the right time and at the right form and using appropriate channels.

The KM challenge for the next years is a "Big Data" problem: many organizations do not have a strategy, so they store everything and are unable to effectively use the knowledge. The real problem is how to organize and search across all the immense data and knowledge. Nowadays, an average knowledge organization employing "1,000 knowledge workers wastes over $\$ 5.7$ million annually searching for but not finding information"; and " $36 \%$ of a typical knowledge worker's day is spent looking for and consolidated information spread across a variety of systems - with those workers only finding information required to do their jobs only $56 \%$ of the time" (Lin, 2018). The development of AI is what will enable the companies to make use of enormous amounts of data (Miller, 2019). Machine learning, deep learning, cognitive computing, and edge computing are what makes artificial intelligence possible. Effective KM strategy in the future will integrate multiple apps and documents located in the cloud locally, and spread across multiple and varying platforms to help make data-driven decisions.

The next important trend is the development of the digital workplace. It is related to connecting people on their preferred platform and in their preferred environment via mobile technologies. Digital Workplace Strategist, Chris Tubb defined the digital workplace as the, "collection of all the digital tools provided by an organization to allow its employees to do their jobs" (Freed, 2015, para. 2). In this approach, KM is not just limited to the intranet the way it was just a few years ago. The development of social media will further influence knowledge sharing. Social networking sites are highly effective tools for communication, and they are also very easy to use. As a result, the "social" element can be integrated with knowledge management software in organizations (Paliszkiewicz \& Koohang, 2016).

The major issue for the coming years will be information security (Paliszkiewicz, 2019). Implementing content management, voice control features, digital workplace, or virtual assistants will not be possible for companies without a security policy and without teaching people how to behave in the Internet to be safe (Lamont, 2018). The main issue for the next five years will be integrating technologies with the company culture and creating a culture of learning and collaborating to ensure that companies will thrive in the digital transformation. Douglas Weidner, Chief Executive Officer (CEO) of the KM Institute, indicated that the challenge will also be how to transform all employees into personal knowledge managers (Prentice, 2018). 


\section{KM Applications}

Knowledge management systems are becoming more collaborative tools and more "social" than ever, allowing to work and communicate with each other in real time. In this area, there are many new possibilities for development in the next few years, including:

- Developing the digital workplace and digital transformation (new platforms, which will integrate different sources of knowledge) (Müller et al. 2018; Peromingo \& Pieterson, 2018);

- Implementing the appropriate tools for people who are able to share their knowledge in real time to encourage employees to narrate their work and broadcast what they are doing so others can interact, learn and apply that knowledge to their work (Garfield, 2018);

- Applying artificial intelligence to automate certain KM tasks (McHenry, 2016);

- Applying analytics and business intelligence, which help KM use data to make decisions (Eidizadeh, Salehzadeh, \& Chitsaz-Esfahani, 2017);

- Adopting enterprise social networks (similar to Facebook) to enhance people for knowledge sharing (Razmerita, Kirchner, \& Nielsen, 2016);

- Adopting gamification and digital badging to enhance people engagement in the work (Harman, Koohang, \& Paliszkiewicz, 2014);

- Adopting mobile apps and the bring your own device (BYOD) trend to ensure that knowledge systems are optimized for mobile, so that knowledge is accessible through the devices and platforms people want to use (Khaddage, Müller, \& Flintoff, 2016).

The new trends in knowledge management are directed to provide more meaningful work space for employees and engage them to enjoy their work (Prentice, 2018). This should also enable the companies to be more efficient, secure and agile.

\section{KM Education}

Over the past 20 years, KM has been part of many university offerings. In the research by Cervone (2017), seven KM-related programs started back in 2001. Over the years, KM programs have morphed into various related programs in analytics, organizational learning, information architecture, and information management, among others.

Looking ahead in the next fix years, KM will probably continue to be integrated into various emerging and existing disciplines, such as data/business analytics, artificial intelligence/machine learning, innovation management, and augmented intelligence/decision support. Unfortunately, the academic publications in KM has been declining since 2012 (see Ribiere's work in Liebowitz, 2016), even though there are over 10 international journals focused on knowledge management (certainly, the most prominent being the Journal of Knowledge Management, Knowledge Management Research and Practice Journal (KMRP), and VINE: Journal of Information and Knowledge Management Systems (Serenko \& Bontis, 2017)).

To show the direction for knowledge management, Bangkok University has a $\mathrm{PhD}$ program in Knowledge and Innovation Management (http://phdkim.iki-sea.org/). As knowledge 
management has been tied to increasing innovation in organizations (see Holsapple, Hsiao, \& Oh, 2015), future education trends should link knowledge management with creativity. Creativity-based organizations, such as Cirque du Soleil in Montreal, have applied KM over the years in order to stimulate creativity and integrate important themes across their various performances.

Related to creativity and innovation is a growing area of intuition-based decision making where KM can play a role (Gigerenzer, 2008; Liebowitz, 2014; Liebowitz et al., 2017; Liebowitz et al., 2019; Liebowitz, 2020). KM's main contribution in this growing research stream is tied to experiential learning. KM is predicated on learning from successes and failures. A growing area for research and education in incorporating one's experiential learning deals with executive decision making. As data-driven and data-informed decisions are made, the intuition of the executive is often cast aside. However, various research from Liebowitz et al. (2019) demonstrates that executives typically trust their intuition over analytics, especially as internal data quality is often suspect. Here, intuition-based executive decision making can play an important complementary role with analytics in making successful decisions. KM, through its knowledge sharing and lessons learned tenets, could be integrated with this emerging area of research and education.

In analyzing where the KM programs were being offered in 2001 and 2016, about half of the KM programs were in Information/Library and Information Science faculties (Cervone, 2017). The next largest home faculty for KM was Business/Management. By 2016, Business/Management exceeded Information/Library and Information Science in terms of housing KM programs, with the next largest shares coming from Professional Studies and Communication Studies (Cervone, 2017). In the near future, there will probably be fewer standalone KM programs, as KM courses will be integrated into analytics, AI, and organizational development programs.

\section{KM Policy}

In November 2018, the International Organization for Standardization (ISO) published ISO 30401 (Knowledge Management Systems) in "setting requirements and providing guidelines for establishing, implementing, maintaining, reviewing, and improving an effective management system for knowledge management in organizations" (ISO, 2018). Moria Levy, Chair of the Israel KM Association, was one of the key developers of this new international standard. As part of this ISO (2018) standard, the policy section stated:

Top management shall establish a knowledge management policy that:

a) is appropriate to the purpose of the organization;

b) provides a framework and guiding principles for setting, reviewing and achieving knowledge management objectives;

c) includes a commitment to satisfy applicable regulatory and other requirements;

d) sets expectations for all workers with regard to use of the knowledge management system and the cultivation of a culture that values knowledge;

e) includes a commitment to continual improvement of the knowledge management system; 
f) manages the balance between knowledge sharing and knowledge protection. (p. 8)

Previously in 2015, ISO had published ISO 9001, which includes an organizational knowledge clause (Wilson and Campbell, 2016). This clause (7.1.6) focuses on ensuring that an organization follows steps to capture and preserve knowledge. Specifically, it states (Hammar, 2016; Wilson \& Campbell, 2016):

- Determine the knowledge that you need to operate your processes and make your products or services conform to requirements;

- Maintain this knowledge and make it available as needed;

- Consider your current knowledge when making changes and determine how you will gain additional or updated knowledge if necessary, for the changing needs.

Even though organizations should have a knowledge retention policy as part of their overarching human capital strategy, many organizations still have been slow to embrace this idea. A knowledge retention policy should be in place from day one of the employee's tenure with the organization (Liebowitz, 2004; Liebowitz, 2008). Egeland (2017) pointed out that awareness is a key starting point for all retention and transfer activities, and leadership plays a critical role. Certain industries, such as the nuclear energy industry, have recognized the importance of preserving knowledge through their Nuclear Knowledge Management (NKM) efforts, as promulgated by the U.N. International Atomic Energy Agency (IAEA, 2019). They offer a School of Nuclear Knowledge Management, conduct Knowledge Management Assist Visits, run conferences on NKM, and take a pro-active role in reducing knowledge loss (see IAEA, 2017).

In the ensuing years, knowledge management policies and practices will be integrated with existing project management and risk management strategies. NASA already does this with their Academy for Program and Project Engineering Leadership (APPEL) (2019). Hopefully, other organizations will develop KM policies that fit their organization's strategic goals and objectives to ensure that $\mathrm{KM}$ will be woven within the integrated fabric of the organization.

\section{Summary: Implications for LIS Educators and Professionals}

Knowledge management is very important for LIS educators and professionals (Shanhong, 2000; Syed \& Mahmood, 2013). Sarrafzadeh, Martin, and Hazeri (2006) indicated that there is a developing interest in knowledge management among LIS professionals, because:

(1) LIS professionals could and should enter into knowledge management roles through their information management skills;

2) there are potential benefits for LIS professionals from involvement in knowledge management including personal career development and enhancement of the position and status of LIS professionals within their parent organizations; and

3) knowledge management offers potential benefits for the development of libraries and the LIS profession itself. (p. 632)

Since knowledge management focuses on human issues like tacit knowledge, intuition and trust management, a new set of skills and competencies are needed for library practitioners to work in 
knowledge management environments (Roknuzzaman \& Umemoto, 2009). Todd and Southon (2001) described the skills required for KM practice through the viewpoint of LIS professionals in Australia. Six categories of skills were identified: 1) people-centered skills, such as those of negotiation, sharing, team-working and communication; 2) skills associated with aspects of management of the organization as a whole (management skills); 3) information processing skills; 4) cognitive skills; 5) organization and business skills; and 6) information technology (IT) skills. Teng and Hawamdeh (2002) underlined four different categories: 1) IT literacy, 2) a sharp and analytical mind, 3) innovation and inquiring, and 4) possibility for knowledge creation, flow and communication within the organization and between staff and the public.

The new challenges for LIS professionals are related to the development of the digitalized world. Library professionals need to be better educated in this area (Matteson, Schlueter, \& Hidy, 2013). It was identified, for example by Nazim and Mukherjee (2013), that traditional LIS skills may be the basis of initiating KM practice in academic libraries, but these are not sufficient and there is a need to develop additional competencies by LIS professionals for KM practice in academic libraries. The librarians have to acquire skills to cope effectively with the knowledge management in libraries and use new technologies to provide better, faster and pinpointed services to its users (Patel, 2015).

As organizations continue their digital transformation, LIS professionals will have to be aware and utilize AI, data analytics, Internet of Things (IoT), and other skill sets, which will add value to $\mathrm{KM}$ in the coming years. Our idyllic vision for the future of $\mathrm{KM}$ is that organizations will not be "talking about KM". Instead, they will just be doing it as part of their organizational fabric and daily work. LIS professionals will continue to have a role in KM in the coming years, but they must integrate and adapt to the emerging organizational environments for KM to succeed and thrive.

\section{References}

APPEL (2019). Knowledge sharing. Retrieved from: https://appel.nasa.gov/knowledge-sharing/

Borko, H. (1968), Information science: What is it? American Documentation, 19(1), 3-5. https://doi.org/10.1002/asi.5090190103

Cervone, F. (2017). What does the evolution of curriculum in knowledge management programs tell us about the future of the field? VINE: Journal of Information and Knowledge Management Systems, 47(4), 454-466.

Davenport, T., \& Prusak, L. (1998). Working knowledge. How organizations manage what they know. Boston, MA: Harvard Business School Press.

Egeland, I. (2017). Knowledge retention in organizations. M.Sc Thesis, University of Stavanger, Spring. Retrieved from: https:/uis.brage.unit.no/uis-xmlui/bitstream/handle/11250/2459 574/Egeland_Ida.pdf? sequence $=1$

Eidizadeh, R, Salehzadeh, R., \& Chitsaz-Esfahani, A. (2017), Analyzing the role of business intelligence, knowledge sharing and organizational innovation on gaining competitive advantage. Journal of Workplace Learning, 29(4), 250-267. 
Freed, E. (2015). Which of these 8 definitions of "digital workplace" works best for you? Retrieved from: https://digitalworkplacegroup.com/2015/03/31/which-of-these-8definitions-of-digital-workplace-works-best-for-you/

Garfield, S. (2018). What are new ideas in knowledge management? Retrieved from: https://medium.com/@stangarfield/what-are-new-ideas-in-knowledge-management652ea47f1baa

Gaviria-Marin, M., Merigo, J. M., \& Popa, S. (2018). Twenty years of the journal of knowledge management: A bibliometric analysis. Journal of Knowledge Management, 22(8), 16551687.

Gigerenzer, G. (2008). Why heuristics work. Perspectives on Psychological Science, 3(1), 20-29.

Goswami, A., \& Agrawal, R. K. (2018). A reflection on knowledge sharing research: Patterns and trends. VINE Journal of Information and Knowledge Management Systems, 48(3), 352-357.

Greene, J. (2019). What is knowledge management and why is it important? Retrieved from: https://www.askspoke.com/blog/knowledge-management/knowledge-managementimportance/

Hammar, M. (2016), How to manage knowledge of the organization according to ISO 9001 Retrieved from: https://advisera.com/9001academy/blog/2016/08/30/how-to-manage-knowledge-of-theorganization-according-to-the-iso9001/

Harman, K., Koohang, A., \& Paliszkiewicz, J. (2014). Scholarly interest in gamification: A citation network analysis. Industrial Management and Data Systems, 114(9), 1438-1452.

Holsapple, C., Hsiao, W. H., \& Oh, J. (2015). Parameters of knowledge management success. Chapter 1. Retrieved from: http://scitechconnect.elsevier.com/wpcontent/uploads/2016/ 05/Chapter-1_kmbookfinalholsappleParameters-of-Knowledge-ManagementSuccess....pdf

International Atomic Energy Agency (IAEA) (2017). Knowledge loss risk management in nuclear organizations. IAEA Nuclear Energy Series NG-T-6.11. Retrieved from: https://www.iaea.org/publications/10921/knowledge-loss-risk-management-in-nuclearorganizations

International Atomic Energy Agency (IAEA) (2019). Nuclear knowledge management section. Retrieved from: https:/www.iaea.org/about/organizational-structure/department-ofnuclear-energy/division-of-planning-information-and-knowledge-management/nuclearknowledge-management-section

ISO (2018) Knowledge management systems - requirements. Retrieved from: https:/www.iso.org/standard/68683.html

Jantz, R. (2001). Knowledge management in academic libraries: Special tools and processes to support information professionals. Reference Service Review, 29(1), 33-39. 
Khaddage, F., Müller, W., \& Flintoff, K. (2016). Advancing mobile learning in formal and informal settings via mobile app technology: Where to from here, and how? Journal of Educational Technology \& Society, 19(3), 16-26.

Koenig, M. E. D. (2002). The third stage of KM emerges. KMWorld, 11(3), 20-21.

KM (2018). Here's why knowledge management is super important. Retrieved from: http://helpiewp.com/importance-knowledge-management-system-need/

Lamont, J. (2018). KM: Looking to the future. KMWorld, 27(1), 1-2. Retrieved from: http://www.kmworld.com/Articles/Editorial/Features/KM-looking-to-the-future122619.aspx

Leonard-Barton, D., Swap, W. \& Barton, G. (2014). Critical knowledge transfer: Tools for managing your company's deep smarts. Boston, MA: Harvard Business Review Press.

Liebowitz, J. (ed.) (1999). The knowledge management handbook. Boca Raton, FL: CRC Press.

Liebowitz, J. (2004). Addressing the human capital crisis in the federal government: $A$ knowledge management perspective. Burlington, MA: Butterworth-Heinemann: Elsevier.

Liebowitz, J. (2008), Knowledge retention: Strategies and solutions. Boca Raton, FL: CRC Press.

Liebowitz, J. (ed.) (2012). The knowledge management handbook: Collaboration and social networking ( $2^{\text {nd }}$ ed.). Boca Raton, FL: CRC Press.

Liebowitz, J. (ed.) (2014). Bursting the big data bubble: The case for intuition-based decision making. Boca Raton, FL: CRC Press.

Liebowitz, J. (ed.) (2016). Successes and failures of knowledge management. Cambridge MA: Morgan Kaufmann/Elsevier.

Liebowitz, J. (ed.) (2018). Data analytics applications - Book series. Taylor \& Francis. Retrieved from: https://www.crcpress.com/Data-Analytics-Applications/bookseries/CRCDATANAAPP?page $=$ \&order $=$ pubdate $\&$ size $=12 \&$ view $=$ list $\&$ status $=$ publishe d,forthcoming

Liebowitz, J. (ed.) (2020). Developing informed intuition for decision making. Boca Raton, FL: Taylor \& Francis.

Liebowitz, J., Chan, Y., Jenkin, T., Spicker, D., Paliszkiewicz, J., \& Babiloni, F. (eds.) (2019). How well do executives trust their intuition. Boca Raton, FL: Taylor \& Francis.

Liebowitz, J., Paliszkiewicz, J., \& Goluchowski, J. (eds.) (2017). Intuition, trust, and analytics. Boca Raton, FL: Taylor and Francis.

Lin, J. (2018). Future of work \#4 - enterprise knowledge management $2.0+$ AI-powered search $\&$ discover $=$ team intelligence. Medium. Retrieved from: https://medium.com/workbench/future-of-work-4-enterprise-knowledge-management-2-0-61 ca08fd2a5d

Ma, Z., \& Yu, K. H. (2010). Research paradigms of contemporary knowledge management studies: 1998-2007. Journal of Knowledge Management, 14(2), 175-189. 
Matteson, M., Schlueter, E. \& Hidy, M. (2013). Continuing education in library management: Challenges and opportunities. Library Management, 34(3), 219-235.

McHenry, W. (2016). Linking decision artifacts: A means for integrating business intelligence and knowledge management. Electronic Journal of Knowledge Management, 14(2), 91102.

Miller, A. (2019). The intrinsically linked future for human and artificial intelligence interaction. Journal of Big Data, 6(1), 1-9.

Nazim, M., \& Mukherjee, B. (2013). Knowledge management competencies required among library and information science professionals. Library Review, 62(6), 375-387.

Nonaka, I. (1991). The knowledge creating company. Harvard Business Review, 69(6), 96-104.

Nonaka, I., \& Takeuchi, H. (1995). The knowledge-creating company: How Japanese companies create the dynamics of innovation. New York, NY: Oxford University Press.

Onyancha, O., \& Ocholla, D. (2009). Conceptualizing 'knowledge management' in the context of library and information science using the core/periphery model. South African Journal of Information Management, 11(4), 1-15.

Paliszkiewicz, J. (2007). Knowledge management: An integrative view and empirical examination. Cybernetics and Systems, 38(8), 825-836.

Paliszkiewicz, J. (2019). Information security policy compliance: Leadership and trust. Journal of Computer Information Systems, 59(3), 211-217.

Paliszkiewicz, J. (2019). Przywództwo, zaufanie $i$ zarządzanie wiedza $w$ innowacyjnych przedsiębiorstwach, [Leadership, Trust and Knowledge Management in Innovative Enterprises], wyd. CeDeWu, Warszawa.

Paliszkiewicz, J., \& Koohang, A. (2016). Social media and trust: A multinational study of university students. Santa Rosa, California: Informing Science Press.

Patel, K. M. (2015). Knowledge management and new skills, roles \& challenges for librarians in the ICT world. International Research: Journal of Library and Information Science, 5(3), 423-436.

Pauleen, D. (2009). Personal knowledge management: Putting the 'person' back into the knowledge equation. Online Information Review, 33(2), 221-224.

Peromingo, M., \& Pieterson, W. (2018). The new world of work and the need for digital empowerment. Forced Migration Review, 58, 32-33.

Prentice, D. (2018). 10 trends to watch in knowledge management. Retrieved from: https://www.arrowsolutionsgroup.com/blog/10-trends-watch-knowledge-management/

Razmerita, L., Kirchner, K. \& Nielsen, P. (2016). What factors influence knowledge sharing in organizations? A social dilemma perspective of social media communication. Journal of Knowledge Management, 20(6), 1225-1246. 
Roknuzzaman, M., \& Umemoto, K. (2009). How library practitioners view knowledge management in libraries. Library Management, 30(8), 643-656.

Sarrafzadeh, M., Martin, B., \& Hazeri, A. (2006). LIS professionals and knowledge management: Some recent perspectives. Library Management, 27(9), 621-635.

Serenko, A., \& Bontis, N. (2017). Global ranking of knowledge management and intellectual capital academic journals: 2017 update. Journal of Knowledge Management, 21(3), 675692.

Scholl, W., König, Ch., Meyer, B., \& Heisig, P. (2004). The future of knowledge management: an international Delphi study. Journal of Knowledge Management, 8(2), 19-35.

Schwarzmüller, T., Brosi, P., Duman, D., \& Welpe, I. (2018). How does the digital transformation affect organizations? Key themes of change in work design and leadership. Management Revue, 29(2), 114-138.

Shanhong, T. (2000). Knowledge management in libraries in the 21st century. Proceedings of the 66th IFLA Council and General Conference, Jerusalem, Israel, Retrieved from: http://ifla.inist.fr/IV/ifla66/papers/057-110e.htm

Syed, R., \& Mahmood, K. (2013). Empirical results of academic librarians' attitudes toward knowledge management in Pakistan. Library Management, 34(8), 619-631.

Teng, S., \& Hawamdeh, S. (2002). Knowledge management in public libraries. Aslib Proceedings, 54(3), 188-197.

Tiwana, A. (2000). The knowledge management toolkit: Practical techniques for building a knowledge management system. Upper Saddle River, NJ: Prentice Hall.

Tuomi, I. (2002). The future of knowledge management. Lifelong Learning in Europe, 7(2), 6979.

Todd, R., \& Southon, G. (2001). Educating for a knowledge management future: Perceptions of library and information professionals. The Australian Library Journal, 50(4), 313-326.

Wang, P., Zhu, F., Song, H., Hou, J., \& Zhang, J. (2018). Visualizing the academic discipline of knowledge management. Journal of Sustainability, 10(3), 1-28. https://doi.org/10.3390/su10030682

Wiig, K. M. (1997). Knowledge management. Expert Systems with Applications, 13(1), 1-14.

Wilson, J., \& Campbell, L. (2016). Developing a knowledge management policy for ISO 9001: 2015. Journal of Knowledge Management, 20(4), 829-844. 


\section{Authors' Biographies}

Dr. Jay Liebowitz is the Distinguished Chair of Applied Business and Finance at Harrisburg University of Science and Technology. He previously was the Orkand Endowed Chair of Management and Technology in the Graduate School at the University of Maryland University College (UMUC). He served as a Professor in the Carey Business School at Johns Hopkins University. His research interests include knowledge management, analytics, intuition-based decision making, and artificial intelligence. Liebowitz received his Doctor of Science from George Washington University. He's also the founder and editor

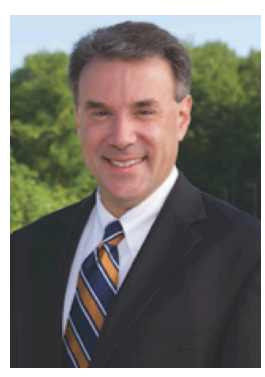
in chief of Expert Systems With Applications: An International Journal. He's a Fulbright Scholar, IEEE-USA Federal Communications Commission Executive Fellow, and Computer Educator of the Year (with the International Association for Computer Information Systems).

Dr. Joanna Paliszkiewicz is a specialist in management issues connected with knowledge management, intellectual capital and trust management. She holds the rank of University Professor of Warsaw University of Life Sciences and Polish-Japanese Academy of Information Technology. Prof. J. Paliszkiewicz is well recognized in Poland and abroad with her expertise in management issues. She has published over 190 original papers and ten books. She serves on the editorial board of several international journals. She is the editor in chief of Issues in Information Systems and deputy editor-in-chief of Management and Production Engineering Review Journal. Dr. Paliszkiewicz was named the 2013 Computer Educator of the Year by IACIS. 